Final version accepted for publication.

\title{
Introduction: identity in applied linguistics
}

\author{
Siân Preece
}

I do not remember paying much attention to the question of 'my identity', at least the national part of it, before the brutal awakening of March 1968 when my Polishness was publicly cast in doubt. I guess that until then I expected, matter-of-factly, and without any soulsearching or calculating, to retire when the time came from the University of Warsaw, and be buried when the time came in one of Warsaw's cemeteries. But since March 1968 I have been and still am expected by everyone around to self-define and I am supposed to have a considered, carefully balanced, keenly argued view of my identity. Why? Because once set in motion, pulled out from wherever I could pass for my 'natural habitat', there was no place where I could be seen as fitting in, as they say, one hundred per cent. In each and every place I was - sometimes slightly, at some other times blatantly, 'out of place' (Bauman 2004: 12).

I applied for asylum on 20 April. I feel isolated, a man in deep despair. Even if France gives me asylum, can I integrate here? Do they see me as a human being? I need some care. At least in Britain even if I was homeless, I could learn the language. Here is hard and the language is so difficult (Fadhel, The Guardian online 27 July 2015). 
Final version accepted for publication.

This Handbook is about identity and its relationship with language. It aims to give readers a comprehensive overview of key topics in the study of language and identity and illustrate how the phenomenon of identity is related to a variety of 'real world problems in which language is a central issue' (Brumfit 1995: 27), Christopher Brumfit's oft-cited definition of applied linguistics. The volume complements The Routledge Handbook of Applied Linguistics (Simpson 2013 [2011]) and is part of the Routledge Handbooks in Applied Linguistics series.

The opening quotes illustrate how identity can become 'a real world problem' and also point to how language comes into the picture. Both are narratives that form part of the rich tapestry of migrant stories on displacement, disjuncture, the search for a new place to belong, the learning of a new language and an identity transformation in which the culture, languages, religion, politics, customs and practices of what was left behind enter into a fluid mix with what is and what is to come. Here then we have two migrant narratives invoking identity. The first comes from Zygmunt Bauman's (2004) classic sociological text, Identity. Bauman tells the story of his migration from Poland to the UK in order to make a point for his audience. As Baumann tells us, those who feel that they belong have no need to worry about their identities. Identity only becomes an issue when a person's sense of belonging is disrupted. For migrants forced to flee, identity disruption is likely to be severe. Baumann's story shows us that once dislocated from his 'natural habitat' of Poland, he 
Final version accepted for publication.

always felt (or was made to feel by others) as 'out of place'. As we will see in this Handbook, it is this 'out of place' feeling that gives rise to identity work and creates opportunities for new subjectivities through the interaction of the 'old' and the 'new'.

The 'out of place-ness' also looms large in Fadhel's narrative. After thousands of miles of migration, Fadhel has become trapped in 'The Jungle', the name given to a make-shift camp in the port of Calais in France, which, at the time of writing, is sheltering 3000 dispossessed and stateless migrants from the poorest and most war-torn regions of the world (Taylor et al. 2015). Fadhel's words (translated into English and placed in subtitles) come from a short film 'Life in the Jungle' (ibid.), posted online by The Guardian. In putting his story into cyberspace, Fadhel asserts his identity as a refugee seeking asylum in France, a man and a human being. In so doing, he gains a fleeting moment of agency in which he is able to tell viewers about his anxieties, particularly his worries about learning French and fitting into French society. He also constructs a future 'imagined self' in Britain, which he believes will afford him the opportunities to learn English even if homeless. In his plea 'I need some care', Fadhel appeals to a common humanity that indexes a global human identity transcending the nation state, in which migrants such as Fadhel are ensnared as:

the 'sans-papiers' - the non-territorials [who live] in a world of territorially grounded sovereignty. While sharing the predicament of the 
Final version accepted for publication.

underclass ${ }^{1}$, they are, on top of all the other deprivations, denied the right to a physical presence within the territory under sovereign rule except in specially designed 'non-places', labelled as refugee or asylum-seeker camps to distinguish them from the space where the rest, the 'normal', the 'complete' people live and move (Bauman 2004: 39).

In both narratives, we see Bonny Norton's (2013: 45) contention that identity refers to:

how a person understands his or her relationship to the world, how that relationship is constructed across time and space, and how the person understands possibilities for the future.

Bauman shows us his ability to relate identity as a theoretical concept to lived experience, to chart the moment of rupture that made him conscious of his identity and how his identity has developed over time and space. He seems to imagine the possibilities for the future as more of the same, i.e. the need to continue maintaining his identity due to feeling 'out of place'. In Bauman's case, however, his future possibilities appear brighter than Fadhel's given the material circumstances of his life and his social status as Emeritus Professor of Sociology at the University of Leeds. Fadhel, on the other hand, has no material comforts or resources to fall back on. His relationship to the world is 
Final version accepted for publication.

of a stateless person who is forced to live a precarious and liminal existence in 'The Jungle' while he waits to see whether or not he will be granted asylum in France. The time and space continuum for Fadhel has been compressed into daily survival and when he imagines possibilities for the future, his best case scenario is homelessness in Britain.

One of the points that we can take from Bauman and Fadhel's stories is that identity is not a free for all in which individuals are at liberty to mix and match designer identities of their choosing. As we will see in this volume, the identities that people 'inhabit' (that is choose for themselves) (Blommaert 2006) are constrained, among other things, by their:

- Access to the types of social spaces and relations (or discursive spaces) in which identities are constructed, constituted, negotiated, accomplished and/or performed;

- 'Ascribed' identities (that is the identities that individuals are given by others (ibid.). Ascribed identities often position individuals as non normative and limit their rights to participation);

- Access to material resources, including the income, property and employment status derived from their social class positioning in society. David Block (2014, this volume) gives us a timely reminder that we need to pay closer attention to social class in research on identity, particularly when investigating "migrants as bilinguals' (2014: 126). 
Final version accepted for publication.

As Block (2007) tells us in his book, Second Language Identities, identity has long been of interest in the social sciences. Social scientists are interested in identity because it enables the gap between the micro level of the individual and the macro level of the social order to be bridged. It allows for the investigation of an individual's membership of particular groups, affiliations to cultural customs and practices and representations of self and others. Block (ibid.) explains how social scientists have come to see identity as fluid, multidimensional (including e.g. gender, sexuality, class, race, ethnicity, age, religion, culture etc.) and socially constructed; these views have taken hold in applied linguistics.

In this volume, we will see the shift in applied linguistics from viewing identity as a set of fixed characteristics that are learned or biologically based to seeing identity as a social construct. This shift reflects the way that identity has become an altogether more complex phenomenon as a result of the mobility and diversity that has arisen in the social worlds of the physical and digital due to the processes of globalisation in late modernity. As we will see, this change in thinking is often discussed in terms of 'essentialism' and 'non essentialism'. Mary Bucholtz (2003: 400) points out that essentialism rests on the assumption that:

the attributes and behavior of socially defined groups can be determined and explained by reference to cultural and/ or biological characteristics 
Final version accepted for publication.

believed to be inherent to the group. As an ideology, essentialism rests on two assumptions: (1) that groups can be clearly delimited; and (2) that group members are more or less alike'.

In contrast, non essentialism chimes with Stuart Hall's (1996: 4) oft-cited definition of identities as:

about questions of using the resources of history, language and culture in the process of becoming rather than being: not 'who we are' or 'where we came from', so much as what we might become, how we have been represented and how that bears on how we might represent ourselves'.

Non essentialised views of identity, such as Hall's, are shaped by poststructuralist and social constructivist theoretical perspectives. These perspectives are discussed in detail in part one of this volume and inform the chapters in the rest of the Handbook.

Since Norton's (1995, 2013 [2000]) pioneering work to inject a social view of identity into SLA, there has been a surge of interest in identity and its relationship with language in applied linguistics. As Norton points out in the 
Final version accepted for publication.

preface to this volume, this has resulted in a considerable number of books, journal articles and special issues devoted to the subject of identity in the field. Zotzmann and O'Regan (this volume) discuss how identity is of particular interest to applied linguists not only because it connects the individual to the social world but also because it frames the use of language as a social, rather than cognitive, enterprise. They put this neatly:

The concept [of identity] sensitises us to think about the reasons for and the conditions under which people use language, the way they are perceived by others as users of language, the meanings they want to convey in particular situations and the resources they draw upon in order to do so (p. x).

If we apply the above to Fadhel's narrative, we can start to draw some tentative conclusions about a number of points as follows. Firstly, Fadhel's reasons for learning French seem likely to be in anticipation of a new life in France should his claim for asylum be granted. As Fadhel tells us, this will require him 'to integrate' with French people, and hopefully give him the chance to return to a normal life in which he has gainful employment, an income and decent housing. Should Fadhel stay in France, French will enable him to inhabit identities that are not currently available to him as a non French speaker. Secondly, the conditions under which Fadhel uses French appear constrained by the very limited access to interactions that he is likely to have with French 
Final version accepted for publication.

people. However, he may be able to use French with Francophone migrants in 'The Jungle' and, as there are volunteer teachers giving French classes in the camp, perhaps he has access to French lessons. With regard to the ways in which Fadhel is perceived by others as a user of language, he is likely to be ascribed the identity of a second language learner, at least by French people. When it comes to the meanings that Fadhel wants to convey, we know from what he has told viewers that he wishes to convey the difficulties of his current life and how to go about resolving these. As he has stated that he is 'in despair', we can infer that he wishes to communicate more than functional and transactional messages. Finally, with respect to the resources that Fadhel has to draw on for language learning, while we do not know anything about his level of education or country of origin, it is likely that Fadhel has a bi/multilingual linguistic repertoire at his disposal as well as other multimodal resources, such as signing and gesture.

To the points given by Zotzmann and O'Regan, we could also add perceptions about language. In Fadhel's case, his narrative invokes the commonly held view of languages as entities that are (1) named (French, English etc.); (2) distinct from each other, suggesting a commonly held view that languages should be kept separate; (3) learned in a particular order (L1, L2, L3 etc.) and (4) attached to particular groups of people as markers of national, ethnic and/ or cultural identity. Fadhel's statement about French being 'difficult', his life in France being 'hard' and his question of whether French people view him 'as a 
Final version accepted for publication.

human being' suggests ambivalence about inhabiting a French or Francophone identity.

Following Norton (2013 [2000]), we begin to get a sense of how language plays a role in Fadhel's identity as a language learner. The argument that Norton puts forward about language appears particularly pertinent to Fadhel's situation:

it is through language that a person negotiates a sense of self within and across different sites at different points in time, and it is through language that a person gains access to - or is denied access to powerful social networks that give learners the opportunity to speak. Thus language is not conceived of as a neutral medium of communication, but is understood with reference to its social meaning' (ibid.: 45).

Language is foregrounded in this Handbook. As we will see, there has been a move from seeing language as discrete entities that mark the ethnic, cultural and/ or national identities of particular groups of people in an unproblematic way to viewing language as part of a repertoire consisting of linguistic and other multimodal resources for communicative and identity work (Rymes 2010). Many of the contributors to this volume draw on the principles 
Final version accepted for publication.

synthesised by Bucholtz and Hall (2010 [2005]: 19-26) for locating identity in language. These can be summarised as follows: (1) 'the emergence principle', in which identity is seen as emerging in interaction. While Bucholtz and Hall refer to talk, this could be extended to interaction between a reader and text. (2) 'The positionality principle': This involves speakers temporarily inhabiting particular roles and stances in the unfolding interaction along with locally situated cultural positions and social order identity categories. (3) 'The indexicality principle': Bucholtz and Hall discuss how identities are 'indexed' in interaction by speakers making overt references to particular identity roles and inscriptions or through covert suggestions about self and others. Indexing can also involve making evaluations about what identities are considered to be normative and non normative as well as using language associated with a particular group identity or persona. (4) 'The relationality principle': This relates to the claim that identities are always constructed in relation to other identity positions and involve a number of overlapping binaries such as selfother, authenticity-inauthenticity and legitimate-illegitimate speaker. (5) 'The partialness principle': This is the idea that as identities are always in a process of becoming, they can only ever be partial.

So far, I have introduced identity and its relationship with language. In what follows we turn to the scope of this volume and a summary of the chapters. 
Final version accepted for publication.

\section{The scope of this volume}

This Handbook is aimed at a diverse audience, including graduate students, early career researchers, established academics, policy makers and practitioners, although the contributions have been written with relative newcomers in mind. The volume brings together a body of work on language and identity in applied linguistics and associated work in sociolinguistics. As might be expected, bi/ multilingual and transnational individuals; second/ foreign language learners and teachers; ethnicity, culture and migration feature regularly. However, the volume also includes other areas of interest in applied linguistics including gender, sexuality, social class, age and disability; professional settings other than the classroom; the digital world and multimodality.

The contributors demonstrate the interest in applied linguistics with theorising practice, particularly what the examination of linguistic practices and perceptions about language can tell us about identity. Several chapters suggest how studies of identity in applied linguistics and sociolinguistics could usefully be applied to practice in professional life, in areas ranging from (language) teacher education, the development of postgraduate and early career researchers and the continuing professional development of practitioners, such as mediators. 
Final version accepted for publication.

Other contributors approach application through the lens of social justice.

These chapters deal with the identities of marginalised or liminal individuals, such as Fadhel. Here the theory/ practice link is seen as a matter of:

1. Identity politics (increasing the recognition of and respect for the identity of an individual or group);

2. The redistribution of wealth (developing policies and practices that seek to redistribute institutional and societal resources to those that are materially disadvantaged in society) (Fraser 1995; Fraser and Honneth 2003).

Block (2014, this volume) gives us a timely reminder that applied linguistics has given more attention to the former than the latter and invites us to focus more fully on the redistribution issue in future work.

Other contributors are concerned with problematising commonly held views in applied linguistics that inform work on language and identity, such as the idea of languages as discrete entitities (as expressed in L1 and L2), the privileging of language as a mode of communication and the focus on the 'real' world. These contributors invite us to consider how 'heteroglossia' (Bakhtin 1984); multimodality and the inclusion of the digital world could transform our understanding of language, identity and their interrelationship, particularly in the superdiverse contexts in which many language and identity studies take place. 
Final version accepted for publication.

While broad in scope, the Handbook is not designed to be exhaustive and there are inevitably some gaps and shortcomings. For instance, while the contributors to this volume represent scholars at all stages of their careers (from $1^{\text {st }}$ year doctoral students to world renowned professors) and include more female than male authors, the number of contributors based in universities in the English-dominant world (here taken to be the United States, the United Kingdom, Anglophone Canada, Australia and New Zealand) outweigh those from institutions in non English dominant contexts; there is also greater reference to language and identity work within the Anglophone 'centre' than outside it and within 'first world' rather than 'third world' contexts. Nonetheless, the five parts of the volume cover a considerable amount of ground, highlighting a wealth of language and identity research in applied linguistics and sociolinguistics in a diverse range of settings. An outline of the five parts of the volume follows.

\section{Part 1: Perspectives on Language and Identity}

The first part of the Handbook consists of seven chapters that present readers with a range of theoretical perspectives on identity and the nature of its relationship with language. The purpose of this section is to give an indication of the diversity of theoretical perspectives available for theorising identity along with a detailed overview of some of these. The chapters in this part of the volume follow a similar format: introduction; overview of the theoretical 
Final version accepted for publication.

perspective under examination; discussion of issues and ongoing debates in relation to applied linguistics. Similarly to all the chapters in the volume, each chapter concludes with a summary; a list of related topics (indicating other related chapters in the volume that readers may find useful to read); an annotated bibliography of further reading for readers to consult for more detailed treatment of the topic and a list of chapter references.

In the opening chapter of the volume, Historical Perspectives on Language and Identity, John Joseph sets the scene for readers by providing a detailed account of how contemporary views of identity, along with the ways in which language is used to index identity, are rooted in historical narratives. Joseph discusses how these narratives are revealed through the beliefs that individuals espouse about languages and the ways in which beliefs about languages are used to signal membership in a collective identity. Joseph charts the shift in the social sciences (and applied linguistics) from structuralist views of identity (in which, as mentioned above, identity was seen as a set of genetically inherent and/ or learned characteristics that were possessed by the individual in a stable and bounded inner core) to social constructionist perspectives on identity (in which identity has come to be viewed as fluid and emerging in interaction).

The idea of fluidity is taken up by Judith Baxter in her chapter, Positioning Language and Identity: Poststructuralist Perspectives, in which the reader is given a comprehensive overview of the ways in which poststructuralism 
Final version accepted for publication.

approaches identity and its relationship with language. Baxter shows us that despite there being no one simple definition of poststructuralism, nor a unified poststructuralist perspective on identity, poststructuralist perspectives on identity have become highly influential in the field. She details how Michel Foucault's (e.g. 1980, 1984) seminal theory of discourse has given rise to a discursive view of identity, in which individuals are viewed as taking up 'subject positions', or 'ways of being an individual' (Weedon 1997), in the discourses to which they have access. As Baxter points out, discourses are viewed as a means by which particular ways of viewing the world get into circulation. By adopting a particular subject position, the individual is therefore not just doing identity work, but also playing an instrumental role in maintaining and reproducing discourse and its attendant ideologies, in society.

The shift from relatively fixed views of identity to those that are more fluid is also charted in Identity in Variationist Sociolinguistics. Here Rob Drummond and Erik Schleef document the changing views of identity in three waves of variationist sociolinguistics, from the initial correlation of language variety with broad demographic identity categories, such as gender and social class, to the idea of language variation being reflective of insider identities in local social networks, to the notion of language variation, such as 'styling', being a resource for identity work in spoken interaction. 
Final version accepted for publication.

Concern with fine-grained analyses of identity in everyday talk is taken up in three related chapters: Ethnomethodological and Conversation Analytic Approaches to Identity, Language and Identity in Linguistic Ethnography and Discursive Psychology and the Production of Identity in Language Practices. In the first of these chapters, Bethan Benwell and Elizabeth Stokoe point out that ethnomethodological approaches view identity as of relevance only insofar as individuals in their everyday activities 'orient to and describe, classify, or assess each other as particular kinds of people, as members (or not) of identityrelevant categories' (p. x). As they point out, this is at odds with the perception of identity as the acculturation of an individual into socially constructed identity categories or with Foucauldian-inspired ideas of identity in poststructuralist accounts. Benwell and Stokoe explain how conversation analysis and membership category analysis, informed by ethnomethodology, have developed linguistic tools for fine-grained analysis of talk. As the reader will see, unlike poststructuralist approaches to identity, ethnomethodological ones require that any claims about identity must be rooted in overt references in the data; the researcher is not permitted to impose identity categories if these are not made salient by the participants themselves.

In the following chapter, Miguel Pérez-Milans argues that linguistic ethnography offers a way of moving beyond the impasse that has arisen in the field between ethnomethodology/CA and poststructuralist, particularly Foucauldian-inspired, approaches to identity. Pérez-Milans explains how linguistic ethnography views a person's activities in terms of social practices, 
Final version accepted for publication.

in which individuals are viewed as participating with some degree of agency and reflexivity. From this perspective, language comes to constitute social practices and also '[serve] as a terrain for working out struggles that are fundamentally about other things' (Heller 2011: 49). Pérez-Milans sets out how linguistic ethnographers combine the linguistic tools of ethnomethodology with ethnographic approaches to examine identity in the situated practices of everyday life.

A similar stance is taken by Jean McAvoy in her chapter. Similarly to CA and linguistic ethnography, McAvoy explains the importance of an explicit focus on language practices and 'what is accomplished in language-in-use' ( $\mathrm{p} . \mathrm{x}$ ) for the study of language and identity in discursive psychology. Identity is viewed as emerging from talk as it unfolds and also as a resource that individuals draw on to position themselves as particular kinds of people. McAvoy discusses how discursive psychology draws on ethnomethodology and the linguistic tools of CA to see how identity is accomplished in talk; linguistic ethnography, with its notion of identity as emerging from participation in situated practice, and various psychological paradigms related to 'personality, beliefs, attitudes, emotions and ... understandings of self, others and relationships' (p. x). As McAvoy points out, discursive psychology allows applied linguists to draw on pyscho-social frameworks for making sense of identity. 
Final version accepted for publication.

Part one is brought to a close with Critical Discourse Analysis and Identity. In this chapter, Karin Zotzmann and John O’Regan set out, by now, a number of familiar ideas about identity, discussing how CDA views identity as located in the social world, as fluid and emergent and as situated in social practices in discourse; however, unlike poststructuralist perspectives, CDA also brings in the material world. Similarly to the other chapters in this part, they point out the role of language as a semiotic resource for doing identity work and the need for a set of linguistic tools that not only allow for the analysis of identity in talk but also how identity is represented in multimodal texts. Unlike the other perspectives discussed so far, which have privileged talk and interaction, CDA places more emphasis on the analysis of written (and multimodal) texts.

However, as Zotzmann and O'Regan argue, it is CDA's 'explicit commitment to a critique of problematic social practices with a view of transforming them for the better' (p. x) that distinguishes CDA from the other theoretical perspectives discussed in this part of the volume. A commitment to the transformation of the social world is therefore uppermost in CDA-inspired studies of language and identity.

\section{Part 2: Categories and Dimensions of Identity}

Part two of the Handbook develops the discussion set out in part one by focusing on the view of identity as 'multidimensional'. This part consists of eight chapters, with each focusing on a particular identity inscription. The chapters follow a similar format: introduction; an account of the category or dimension of identity under examination; ongoing issues and debates with 
Final version accepted for publication.

regard to applied linguistics; summary; related topics; further reading and references. The first five chapters in part two are broadly concerned with race, ethnicity, culture and religion as dimensions of identity for bi/multilingual individuals, groups and communities in the global world. In Language and Ethnic Identity, Vally Lytra shows how ethnicity continues to be an important dimension of identity in contemporary life. Tracing shifts in thinking about ethnicity in the social sciences, Lytra examines the role that language plays in marking ethnic identities. Picking up on themes introduced by Joseph in part one of the volume, Lytra compares essentialist and constructionist views of ethnic identity. She shows how essentialised views of identity approach languages as separate entities that are used to mark particular ethnic and cultural identities whereas constructionist perspectives view language and ethnicity as having porous borders that allow for the negotiation of more fluid, and hybrid, ethnic identities, which as Lytra point outs, are characterised by linguistic diversity and multilingual repertoires.

In Language, Race and Identity, Tope Omoniyi presents a discussion of the arguments in various disciplines on race, examining problems with definitions of race that rely on stereotypes to views of race as a complex social construct. Omoniyi shows how interest in race in sociolinguistics and applied linguistics goes beyond the study of racism discourses and argues that the interface of race, language and identity affords opportunities for issues related to social justice to be addressed by applied linguists. 
Final version accepted for publication.

In Linguistic Practices and Transnational Identities, Anna De Fina develops the discussion on ethnicity, culture and language by examining transnationalism as a dimension of identity in contexts of migration and mobility. As De Fina points out, transnational identities are not bound to one nation state, ethnicity, culture or language but emerge in the social networks created by migrants to link their ancestral homelands with their place of settlement. Similarly to Lytra, De Fina puts forward a view of identity as fluid and emerging from the culturally and linguistically diverse practices of migrant communities. For De Fina, this allows for a view of migrants as agentive and reflexive transnational individuals rather than as assimilating or resisting the practices and identities of 'people who are firmly grounded in one place' (p. x).

Similar themes are picked up on in Identity in Post-colonial Contexts. In this chapter, Priti Sandhu and Christina Higgins discuss the relationship between identity and language in postcolonial settings, showing how a 'centreperiphery' binary has come to shape understandings of identity inscriptions, such as class, ethnicity, language and gender. Drawing on Edward Said's (1978) seminal text, Orientalism, Sandhu and Higgins explain the development of two important binaries in post-colonial studies: 'Self-Other' and 'OccidentOrient' that have been used to construct a normative western identity in opposition to a non normative eastern other. As Sandhu and Higgins point out, these binaries have become increasingly problematic for theorising identity in contemporary post-colonial settings. In a similar vein to De Fina, Sandhu and Higgins argue that identity studies need to start with the transcultural and 
Final version accepted for publication.

multilingual language practices that are a feature of the setting under examination, including the use of the language of the colonial legacy, such as English, and consider how these index coloniser-colonised relations, ideologies and identities.

Language and Religious Identities examines religion as a dimension of identity, focusing on migrant faith communities. Ana Souza gives a detailed overview of the development of 'language and religion' as a major area of interest in sociolinguistics. For Souza, language and religion have a symbiotic relationship. She shows how in the context of faith communities heritage and community languages are not only an important resource for maintaining religious practices and for establishing religion as a dimension of identity, but also how religious practices play an important role in the maintenance of community and heritage languages and identities.

The following two chapters turn to gender, sex and sexuality as dimensions of identity. In Language and Gender Identities, Lucy Jones presents a detailed overview of how the relationship between language and gender identity has developed in applied linguistics and sociolinguistics since the 1970s. She points out how early scholarship was based on the idea of sex and gender binaries that linked biological sex (the male/ female body) with learned gender (masculine/ feminine identity); language was viewed as reflective of gender socialisation and gender identity as a 'man' or 'woman'. As Jones shows us, 
Final version accepted for publication.

this binary was used to construct the 'gender order' (Connell 1987) and the associated idea of 'heteronormativity' (Cameron and Kulick 2003), in which heterosexuality within monogamous relationships and marriage are presented as norms. Jones discusses how Judith Butler's (1990) seminal work on 'performativity' problematised normative views of gender and sexuality, allowing for a range of masculinities, femininities and transgender identities. As she comments, performativity allows for a view of language as a resource for performing gender identities and for representing gender identities in texts.

Sexuality as a dimension of identity is developed in John Gray's chapter, Language and Non normative Sexual Identities. Gray charts the development of non normative LGBTQI (lesbian, gay, bisexual, transgender, transsexual, queer and intersex) identities and the role of language in representing and expressing non-normative sexual identities through three periods: the work of sexologists in the 19th century; the rise of lesbian and gay studies in the late 20th century and the development of contemporary queer theory. For Gray, non normative sexualities, as a dimension of identity, represent a challenge to the gender order along with its heteronormative ideology and essentialised perceptions of identity.

Part two closes with Class in Language and Identity Research, in which social class is examined as an identity inscription. David Block presents a detailed discussion of social class, examining its origins in the work of Karl Marx and 
Final version accepted for publication.

its subsequent development as a multidimensional and multileveled construct in the work of Pierre Bourdieu and other scholars. Block challenges the lack of attention to class in language and identity studies in the field. Drawing on Nancy Fraser (1995), Block puts forward the argument that class is different from other identity inscriptions in that it attends to the distribution of material resources rather than the recognition of cultural differences. Block argues that language and identity studies would be enriched by greater attention to distribution issues as well as cultural recognition.

\section{Part 3: Researching the Language and Identity Relationship}

Part three of the Handbook acts as a bridge between the theoretical discussion in parts one and two and the discussion in parts four and five on past and current research and possible future directions for language and identity work. Part three consists of five chapters that address some of the problems and dilemmas that language and identity researchers face. The chapters follow a similar format: introduction; account of the issue; commentary on ways of addressing the issue; summary; related topics; further reading and references.

Anna Hultgren, Elizabeth Erling and Qumrul Chowdhury open this part of the Handbook with Ethics in Language and Identity Research, in which they put the question of ethics in the spotlight. Hultgren, Erling and Chowdury invite us not to approach ethical questions as a checklist to be signed off by an ethics committee, but as an opportunity to develop 'ethical literacy' (Wiles and 
Final version accepted for publication.

Boddy 2013), in which ethics becomes an intrinsic part of the research process.

For Hultgren, Erling and Chowdury, ethical literacy enables researchers to become more accountable to their participants along with others who are directly and indirectly involved in their research projects. This is illustrated by a reflection on their own ethical dilemmas on an English language-learning project in rural Bangladesh.

The next chapter, A Linguistic Ethnography of Identity: Adopting a Heteroglossic Frame, invites language and identity researchers to adopt a 'heteroglossic' (Bakhtin 1984) perspective when researching in bi/ multilingual contexts. Angela Creese and Adrian Blackledge argue that heteroglossia allows the researcher to problematise the commonly held perception of bi/ multilingualism in applied linguistics as two plus named languages that exist discretely in people's lives. Picking up on the discussion of language presented so far in the volume, Creese and Blackledge make the case for adopting a linguistic ethnographic approach to language and identity studies in which researchers start by examining the linguistic practices of the participants in the setting, considering how these index identities for the participants themselves and drawing on a heteroglossic frame to consider the language ideologies informing the participants' perceptions. They argue that this will allow for a more critical stance towards the classification of research participants in language and identity studies in contexts of superdiversity and a more nuanced discussion when it comes to using research findings to influence policy and practice in professional domains. 
Final version accepted for publication.

In The Politics of Researcher Identities: Opportunities and Challenges in Identities Research, Frances Giampapa gives a detailed account of the role of the researcher in language and identity studies in language learning contexts. She argues that researchers are positioned socially, politically and historically in their research and 'inextricably intertwined with the lives and everyday practices of their research participants' (p. x). Giampapa invites language and identity researchers to think reflexively in order to bring to light the ways in which researcher identities shape the research. This is illustrated by a reflective account of her own research.

\section{Challenges for language and identity researchers in the collection and} transcription of spoken interaction examines common issues that are encountered when collecting and transcribing talk. Eva Eppler and Eva Codó present a detailed discussion of the type of decisions that researchers embarking on a language and identity study need to make. They put forward helpful observations for applied linguists to bear in mind on the sorts of spoken interaction that are useful for answering research questions; the kinds of speakers, contexts and interactions that are likely to generate useful data; different ways of collecting spoken interaction and the variety of approaches to transcription. 
Final version accepted for publication.

The final chapter in this part of the Handbook, Beyond the Micro-macro Interface in Language and Identity Research, focuses on the problems related to linking everyday instances of language with institutional practices and the social order. Kristine Horner and John Bellamy give readers a thorough account of the debate that has taken place in the social sciences on the relationship between two binaries: ‘micro- macro' and 'structure- agency'. Horner and Bellamy critique these binaries and illustrate how researchers in applied linguistics and sociolinguistics have attempted to bridge the life worlds of their research participants with a bigger picture related to the functioning of broader social, political and economic structures. For Horner and Bellamy, ethnographically oriented studies of language and identity that employ discourse analytic methods offer the best chance of addressing the micromacro dilemma.

\section{Part 4: Language and Identity Case Studies}

Part four of the Handbook addresses the interest in applied linguistics with theorising practice. This part consists of eleven chapters, in which the contributors present their own case studies of language and identity research. These showcase the range of work that is taking place in the field, bring theoretical discussion to life, by illustrating how identity and its relationship with language has been realised in research, and act as a model for novice researchers contemplating their own language and identity research. The chapter format in this part of the volume broadly follows that of a journal article: introduction (scene setting and outline of the main argument); literature 
Final version accepted for publication.

review (brief overview of the theoretical perspectives on language and identity informing the study); methodology (a reasonably detailed account of the research process); data presentation (examples of the data showing approaches to data presentation and analysis); discussion (what the data tell us about the overall argument) and issues arising for applied linguistics (some indication of what the field can learn from the study).

As applied linguistics has long been concerned with education, the first five chapters present language and identity case studies undertaken in a variety of educational settings in different parts of the world. In the opening chapter, Constructing Age Identity: The Case of Mexican EFL Learners, Patricia Andrew focuses on age as a dimension of English language learner identities in Mexico. In her nuanced study, Andrew shows that age as a social construct, rather than a biological characteristic, is a significant dimension of identity for language learners and illustrates how age intersects with other identity inscriptions, such as gender in the EFL classroom. Andrew argues that SLA researchers and language teachers need to take greater account of age as a social phenomenon and a more critical stance towards ageist discourses that mark older learners as non normative.

The next two chapters: The Significance of Sexual Identity to Language Learning and Teaching and An Identity Transformation? Social Class, Language Prejudice and the Erasure of Multilingual Capital in Higher 
Final version accepted for publication.

Education pick up on the theme of marginalisation and the marking of particular groups of language learners as non normative. In the first, Cynthia Nelson discusses the importance of sexuality as a dimension of language learners and teachers' identities, drawing on data from her case study of English language classrooms in the United States. Nelson demonstrates how heteronormativity still regulates much of the interaction in the language classroom, thus closing down space for the emergence and recognition of LGTBQI identities. Nelson provides readers with powerful evidence of why sexual identity is not peripheral but integral to the language learning and teaching enterprise and suggestions for language teachers on how to approach sexuality as a dimension of language learners' identities. The following chapter presents my own case study into the identities of linguistic minority undergraduate students on an academic writing programme in a university in London. In this chapter, I discuss social class as both an ascribed identity, arising from the participants' positioning in the British social class system, and an inhabited identity that shapes the participants perceptions and use of language and linguistic practices in the context of the university. I show how the participants experience language prejudice in the domain of higher education as a result of institutional practices that stigmatised their linguistic practices and erased their multilingual capital. I conclude by discussing how shifts in institutional culture and resources are required to enable working-class students from bi/multilingual migrant communities to achieve the identity transformation on offer in higher education. 
Final version accepted for publication.

In the following two chapters we move out of the language classroom and into other educational settings. In the first of these chapters, Being a Language Teacher in the Content Classroom: Teacher Identity and Content and Language Integrated Learning (CLIL), Tom Morton presents data from the Bilingual Education Project, a large-scale case study in Spain into the acquisition of bilingual Spanish and English through an integrated contentbased curriculum. Morton examines the impact of CLIL on the identities of subject teachers as they grapple with teaching their subject in English. Morton illustrates how identity issues emerge in interactions between the teacher and school pupils and in reflective talk on teaching practice. Morton argues that attending to teacher identities in CLIL contexts bridges the worlds of applied linguists and language educators in the field of bilingual education and opens up possibilities for collaborative research. Following this, we move to a case study set in a special school in Sweden for children with learning disabilities. In this chapter, Disability Identities and Category Work in Institutional Practices: The Case of a 'Typical ADHD Girl', Eva Hjörne and Ann-Carita Evaldsson examine disability as a dimension of identity. Employing an ethnomethodological framework, they show how Attention Deficit Hyperactivity Disorder as a disability category is accomplished in the talk at school and in interactions between the school and parents. Hjörne and Evaldsson illustrate the intersection of disability with gender through examining how the school uses disability and gender categories to explain and address behaviour that is deemed to be problematic. They make a powerful case for the way in which the identity of a 'typical ADHD girl' is accomplished 
Final version accepted for publication.

by the school and how this comes to stigmatise and marginalise the preadolescent girl concerned.

In the next two chapters, we turn to case studies set in other professional and institutional domains. In the first of these, Comes With The Territory': ExpertNovice and Insider-Outsider Identities in Police Interviews, Frances Rock shows how witness identities are constructed in interviews between police officers and witnesses to crimes in England and Wales. Through analysis of talk in the interview setting, Rock illustrates how witnesses who adopt an expert-insider witness identity rather than a novice-outsider identity can challenge conventional asymmetries in the interview setting. The following chapter, Language, Gender and Identities in Political Life: A Case Study from Malaysia, takes us to Malaysia and a case study concerned with the under representation of women in political life. In this chapter, Louise Mullany and Melissa Yoong examine gender as a dimension of identity in the case of Dyana Sofya Mohd Daud, a female candidate who stood for parliament in a byelection in Malaysia. By contrasting digital texts written by Daud with online articles written by journalists, Mullany and Yoong show how a cocktail of identity inscriptions was created in the mass media intersecting gender with profession, age, race, religion and sexuality and how this cocktail served to reproduce the gender order. 
Final version accepted for publication.

The following chapter, Straight Acting: Discursive Negotiations of a Homomasculine Identity, also picks up on gender and sexual identities in digital contexts. In this chapter, Tommaso Milani takes us to the online world of meetmarket, a social networking site in South Africa for men looking for other men. In his case study, Milani examines sexuality as a dimension of identity and its intersection with gender and race in the South African context. Through a detailed linguistic analysis of online corpora and interviews with men advertising on meetmarket, Milani shows how 'straight-acting' has become an important practice among non-heterosexual white middle-class men as a way of countering homophobia in the South African context and resisting exclusion from domains of hegemonic masculinity. However, Milani suggests that in so doing, 'straight acting' serves to reinforce the 'same old gender script' (Cameron 2001).

The following two chapters turn to the ethnic and cultural identities of adult migrants in Anglophone settings in home and community domains. In the first of these, Styling and Identity in a Second Language, Ben Rampton presents a case study drawn from a large ESRC funded project Dialect development and style in a diaspora community, which investigated the use and development of dialectal varieties of English in families with Indian ancestry in London. Through a detailed linguistic analysis of the style-shifting and L2 variants used by an adult male migrant from the Punjab, Rampton examines the fluidity of identity and the intersection of a range of identity inscriptions for members of migrant communities in London. Rampton argues that applied linguists would 
Final version accepted for publication.

do well to start with 'the total linguistic fact' (Silverstein 1985) when doing language and identity studies. For Rampton, an analysis of the relationship between linguistic form, situated discourse and ideology facilitates a more rounded analysis of migrant identities that avoids "the romantic celebration of difference or creative agency that has been so common in sociolinguistics, and for the presumption of deficit and remedial need in SLA' (p. x). In a related chapter, Construction of Heritage Language and Cultural Identities: A Case Study of Two Young British-Bangladeshis in London, Qumrul Hasan Chowdury examines the intersection of ethnicity with culture, gender, religion and social class for two female British Asians in London whose families originated from Bangladesh. The interjection of class enables Chowdury to show the development of asymmetrical class based relations within the South Asian community based in the UK. For Chowdury, however, religion emerged as the key dimension of identity, which, he suggests, was a response to Islamophobia in the UK context.

In the final chapter in this section, we turn to minoritised languages and their role in maintaining ethnic and national identities. In his chapter, Minority Languages and Group Identity: Scottish Gaelic in the Old World and the New, John Edwards examines the role of Gaelic in constructing Scottish identity in Scotland and Nova Scotia. Edwards presents a detailed discussion of a number of case studies that have surveyed attitudes to Gaelic in these locations. Picking up on the issues discussed by several contributors regarding the nature of the relationship between language and ethnic identity, Edwards argues that Gaelic 
Final version accepted for publication.

occupies a largely symbolic role when it comes to ethnic and national identity for both the Scots in Scotland and Scottish migrants to Nova Scotia. For Edwards, 'language shift - and a lack of general interest in revival efforts - has come to sit quite easily with a strongly continuing sense of Scottish identity' (p. x).

Part 5 Future Directions.

Part five concludes the volume with a series of chapters examining the directions for future work on language and identity in applied linguistics. Part five comprises six chapters with each giving an account of an issue for development in current work and how this could be addressed in future studies. In the opening chapter, Intersectionality in Language and Identity Research, David Block and Victor Corona examine identity as a multidimensional phenomenon in which identity inscriptions are viewed as intersecting and shaping each other rather than as discrete and bounded categories. They argue that intersectionality has normally been dealt with by default in language and identity studies and contend that the field would benefit from theorising intersectionality and addressing it more fully as a methodological practice. Block and Corona examine data from Corona's research on the identities of young Latinos in Barcelona to show how an intersectional analysis can be developed. 
Final version accepted for publication.

The following two chapters, Language and Identity in the Digital Age and Language and Identity Research in Online Environments: A Multimodal Ethnographic Perspective, consider closely related topics. In the first of these chapters, Ron Darvin examines how advances in technology have made a dramatic impact on applied linguistics terrain. Darvin points out that the 'real world' in which applied linguistics has traditionally operated has been radically altered by ongoing developments in the digital domain. Darvin examines changes to the applied linguistics landscape brought about by the virtual world and argues that applied linguistics is well placed to investigate the affordances and constraints for the construction of online identities and the ways in which access to technology is positioning language learners as insiders or outsiders. In the following chapter, Myrrh Domingo questions the pre-occupation with language in applied linguistics in her examination of multimodality. Domingo argues by privileging language as a mode of communication, applied linguists run the risk of not only missing other modes (non verbal resources) that are brought to bear in the construction of identities, but also how these intersect with language. Domingo illustrates the affordances that multimodality creates for investigating language and identity in online environments by presenting data from her ethnographic study of the Pinoys, a Filipino British rap group.

In the following chapter we turn to neoliberalism. Exploring Neoliberal Language, Discourses and Identities presents a critique of the neoliberal policies and practices that have come to shape much of what goes on in institutions around the globe. Christian Chun examines the ways in which 
Final version accepted for publication.

identities are co-constructed within a neoliberal discursive field and how neoliberalism is maintained through neoliberal policies and practices. Chun invites applied linguists to counter the dominance of neoliberal discourses in future language and identity studies by inhabiting identities that are more concerned with 'community-based notions of social justice and freedom' (p. x) and examining how identities are 'branded' in the neoliberal order.

The Handbook closes with two chapters that provide comprehensive agendas for research in language and identity in sociolinguistics and applied linguistics. In The Future of Identity Research: Impact and New Developments in Sociolinguistics, Bettina Beinhoff and Sebastian Rasinger identify three issues for future work: authenticity, fluidity of identities, and the role of the researcher and research ethics. For Beinhoff and Rasinger, researchers need to pay close attention to the authenticity of data and participants in future language and identity projects; continue to treat identity as fluid rather than static and bounded and consider the identity of the researcher more closely and how researcher identities impact on language and identity research, particularly with regard to research ethics. The final chapter, Identity in Language Learning and Teaching: Research Agendas for the Future, devotes itself to familiar terrain in applied linguistics - language learning and teaching. Peter de Costa and Bonny Norton examine four broad strands for future work in language and identity: theoretical developments, interdisciplinarity, research populations and methodological innovations. De Costa and Norton make the case that theoretical perspectives on identity in applied linguistics would be enriched by 
Final version accepted for publication.

further consideration of globalisation, investment and research in postcolonial settings. Language and identity researchers are invited to continue developing interdisciplinary links, diversify the research populations in their studies and revisit prevailing methodologies in language and identity projects to consider how 'the methodological tool kit' (p. x) could be developed. Similarly to other contributors, De Costa and Norton also identify researcher identities as an important area for development, particularly in future work in online settings.

\section{References}

Bakhtin, M. M. (1984). Problems of Dostoevsky's poetics. C. Emerson (ed.)

[Trans. C. Emerson]. Manchester: Manchester University Press.

Bauman, Z. (2004). Identity: conversations with Benedetto Vecchi. Cambridge: Polity Press.

Blommaert, J. (2006). Language policy and national identity, in T. Ricento (ed.) Language policy: theory and method. Oxford: Blackwell, pp. 238-254.

Bucholtz, M. (2003). 'Sociolinguistic nostalgia and authentification of identity', Journal of Sociolinguistics, 7(3): 398-416.

Bucholtz, M. and Hall, K. (2010 [2005]). Locating identity in language, in C. Llamas and D. Watt (eds.) Language and identities. Edinburgh: Edinburgh University Press, pp. 18-28. 
Final version accepted for publication.

Butler, J. (1990). Gender trouble: feminism and the subversion of identity, London: Routledge.

Block, D. (2007). Second language identities. London: Continuum.

Block. D. (2014). Social class in applied linguistics. Abingdon: Routledge.

Block, D. (this volume). Class in language and identity research, in S. Preece (ed.) The Routledge handbook of language and identity. Abingdon: Routledge, pp. $\mathrm{X}-\mathrm{XX}$.

Brumfit, C.J. (1995). Teacher professionalism and research, in G. Cook and B. Seidlhofer (eds.) Principles and practice in applied linguistics: studies in honour of H.G. Widdowson. Oxford: Oxford University Press, pp. X-xx.

Cameron, D. (2001). Working with spoken discourse. London: Sage.

Cameron, D. and Kulick, D. (2003). Language and sexuality. Cambridge: Cambridge University Press.

Connell, R.W. (1987). Gender and power: sexuality, the person and sexual politics. Cambridge: Polity Press.

Foucault, M. (1980). Power/Knowledge: selected interviews and other writings 1972-1977. New York: Pantheon.

Foucault, M. (1984). What is enlightenment?, in P. Rabinow (ed.) The Foucault reader. London: Penguin, pp. 32-50. 
Final version accepted for publication.

Fraser, N. (1995). 'From redistribution to recognition? Dilemmas of justice in a “postsocialist” age', New Left Review, 212: 68-93.

Fraser, N. and Honneth, A. (2003). Redistribution or recognition? A PoliticalPhilosophical Exchange. London: Verso.

Hall, S. (1996). Introduction: who needs 'identity'?, in S. Hall and P. du Gay (eds.) Questions of cultural identity. London: Sage, pp. 1-17.

Heller, M. (2011). Paths to post-nationalism: a critical ethnography of language and identity. Oxford: Oxford University Press.

Norton (Peirce), B. (1995). 'Social identity, investment, and language learning', TESOL Quarterly, 29(1): 9-31.

Norton, B. (2013 [2000]). Identity and language learning: extending the conversation. 2nd edn. Bristol: Multilingual Matters.

Rymes, B.R. (2010). Classroom discourse analysis: a focus on communicative repertoires, in N. Hornberger and S. McKay (eds.) Sociolinguistics and language education. Avon: Multilingual Matters, pp. 528-546.

Said, E. (1978). Orientalism. New York: Vintage.

Silverstein, M. (1985). Language and the culture of gender, in E. Mertz and R. Parmentier (eds.) Semiotic mediation. New York: Academic Press, pp. 219259.

Simpson, J. (ed.) (2013 [2011]). The Routledge handbook of applied linguistics. Abingdon: Routledge. 
Final version accepted for publication.

Taylor, M., Topping, A., Domokos, J. and Mahmood, M. (2015). 'Fortress

Calais: fleeting fixtures and precarious lives in the migrant camp', The

Guardian, 27 July [Online]. Available at

http://www.theguardian.com/world/2015/jul/27/migrant-camp-fortress-calais-

jungle

Vertovec, S. (2006). 'The emergence of super-diversity in Britain', Centre on

Migration, Policy and Study, Working Paper 25, University of Oxford

[Online]. Available at:

https://www.compas.ox.ac.uk/fileadmin/files/Publications/working_papers/WP

_2006/WP0625_Vertovec.pdf

Weedon, C. (1997). Feminist practice and poststructuralist theory. $2^{\text {nd }}$ edn.

Oxford: Blackwell.

Wiles, R. and Boddy, J. (2013). 'Introduction to the special issue: research ethics in challenging contexts', Methodological Innovations Online 8(2) 1-5.

Zotzmann, K. and O'Regan, J. (this volume). Critical discourse analysis and identity, in S. Preece (ed.) The Routledge handbook of language and identity. Abingdon: Routledge, pp. x-xx. 
Final version accepted for publication.

${ }^{1}$ Bauman (2004: 39) uses the underclass to refer to people on the very margins of society (such as drug addicts, beggars, homeless, street prostitutes etc.) who are viewed as 'undesirable'. Bauman argues that the underclass have 'an absence of identity', in that they are denied access to the material resources and type of social spaces in which identities that are coveted are constructed. 